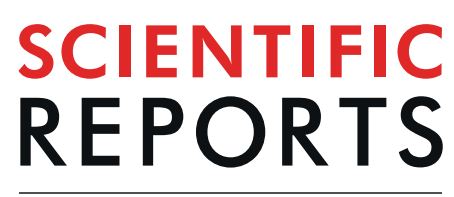

natureresearch

Check for updates

\title{
Darier disease is associated with heart failure: a cross-sectional case- control and population based study
}

\author{
Etty Bachar-Wikstrom ${ }^{1}$, Philip Curmann ${ }^{1,2}$, Tara Ahaniann ${ }^{1,2}$, Ivone U. S. Leong ${ }^{1}$, \\ Henrik Larsson ${ }^{3}$, Martin Cederlöf4 \& Jakob D. Wikstrom ${ }^{1,2 \bowtie}$
}

Human data supporting a role for endoplasmic reticulum (ER) stress and calcium dyshomeostasis in heart disease is scarce. Darier disease (DD) is a hereditary skin disease caused by mutations in the ATP2A2 gene encoding the sarcoendoplasmic-reticulum $\mathrm{Ca2}^{+}$ATPase isoform 2 (SERCA2), which causes calcium dyshomeostasis and ER stress. We hypothesized that DD patients would have an increased risk for common heart disease. We performed a cross-sectional case-control clinical study on 25 DD patients and 25 matched controls; and a population-based cohort study on 935 subjects with DD and matched comparison subjects. Main outcomes and measures were $\mathrm{N}$-terminal pro-brain natriuretic peptide, ECG and heart diagnosis (myocardial infarction, heart failure and arrythmia). DD subjects showed normal clinical heart phenotype including heart failure markers and ECG. The risk for heart failure was $1.59(1,16-2,19)$ times elevated in DD subjects, while no major differences were found in myocardial infarcation or arrhythmias. Risk for heart failure when corrected for cardivascular risk factors or alcohol misuse was $1.53(1.11-2.11)$ and $1.58(1,15-2,18)$ respectively. Notably, heart failure occurred several years earlier in DD patients as compared to controls. We conclude that DD patients show a disease specific increased risk of heart failure which should be taken into account in patient management. The observation also strenghtens the clinical evidence on the important role of SERCA2 in heart failure pathophysiology.

Rare monogenic diseases provide opportunities to study human physiology and pathology from unique perspectives. Besides the importance of diagnosing and successfully treating patients with a rare disorder, major scientific breakthroughs resulting from investigation of rare diseases have often provided insight into more common disorders $^{1-3}$. Herein, we examined increased risk of heart disease as a comorbidity of the rare skin disorder Darier disease (DD).

\section{Darier disease}

Darier (Darier-White) disease (DD) was first described independently by Darier and White in $1889^{4-6}$. It is an autosomal-dominant skin disorder caused by mutations in the ATP2A2 gene, which encodes for sarcoendoplasmic-reticulum $\mathrm{Ca}^{2+}$-ATPase isoform $2(\mathrm{SERCA} 2)^{7}$. DD is characterized by a peculiar keratinization of the epidermis, nails, and mucus membranes resulting in a persistent hyperkeratotic papules ${ }^{8}$. The prevalence of the disease has been estimated to be 1 in 30,000-55,000 and the onset is usually before the third decade of life with complete penetrance in adults ${ }^{9}$. DD never remits, but oral retinoids may reduce hyperkeratosis. Interestingly, DD has been reported to be associated with epilepsy and neuropsychiatric problems including mild intellectual disability, bipolar disease and schizofrenia ${ }^{10,11}$.

\footnotetext{
${ }^{1}$ Dermatology and Venereology Division, Department of Medicine (Solna), Karolinska Institutet, Stockholm, Sweden. ${ }^{2}$ Dermato-Venereology Clinic, Karolinska University Hospital, Stockholm, Sweden. ${ }^{3}$ Department of Medical Epidemiology and Biostatistics, Karolinska Institutet, Stockholm, Sweden. ${ }^{4}$ Centre for Psychiatry Research, Department of Clinical Neuroscience, Karolinska Institutet, and Stockholm Health Care Services, Norra Stationsgatan 69, Stockholm, Sweden. ${ }^{\circledR e}$-mail: jakob.wikstrom@ki.se
} 


\section{Role of SERCA2 in physiology and pathophysiology of the heart}

In the healthy heart, $\mathrm{Ca}^{2+}$ is released from the sarcoplasmic reticulum (SR) via the ryanodine receptor 2 (RYR2), thus raising the cytosolic $\mathrm{Ca}^{2+}$ concentration and activating cardiac muscle contraction. The $\mathrm{Ca}^{2+}$ is then pumped back into the SR by SERCA2a lowering the cytosolic $\mathrm{Ca}^{2+}$ concentration to baseline levels and causing relaxation $^{12}$. SERCA2 protein has three isoforms; SERCA2a, $2 \mathrm{~b}$ and $2 c$. While SERCA2b is expressed ubiquitously in most tissues, SERCA2a is predominantly expressed in cardiomyocytes ${ }^{12}$. Heart failure (HF) is a highly morbid condition with increased incidence after the age of 65 , affecting 1 in 100 individuals ${ }^{13}$. While efforts have been devoted to investigate the therapeutic value of various $\mathrm{Ca}^{2+}$ channels and proteins that regulate cytosolic $\mathrm{Ca}^{2+}$ concentrations, SERCA2a has received the most interest in recent years. Indeed, it was shown that the expression of SERCA2a is downregulated in HF, which subsequently contributes to severe systolic and diastolic dysfunction $^{14-16}$. Consequently, restoring SERCA2a expression by gene transfer, both in HF patients ${ }^{17,18}$, as well as in animal models ${ }^{19}$, is elegantly described; however, with contradicting results. Thus, the role of SERCA2a is still unclear and further investigation is required.

In heart disease, pathological events such as overproduction of reactive oxygen species (ROS), ischemia/reperfusion, release of inflammatory cytokines and toxins, as well as perturbations in $\mathrm{Ca}^{2+}$ homeostasis can trigger endoplasmic reticulum (ER)/SR stress ${ }^{20}$. The latter is defined as an imbalance between the protein load and the folding capacity of the ER, which results in accumulation of misfolded proteins further activating an adaptive response termed the unfolded protein response (UPR). UPR is executed by a signaling network comprised of three ER-localized transmembrane proteins (IRE1, PERK and ATF6), which aim to restore the protein-folding homeostasis. Principally, for efficient cardiomyocyte contractile function, protein quality control is essential, and any perturbations in protein homeostasis can affect functionality and contractility of the myocytes, resulting in cell death ${ }^{21-23}$. Indeed, reduced SERCA2 expression or function causes the phenotype of HF also through induction of ER stress ${ }^{24}$.

With this background, we hypothesized that DD patients, who are characterized by $\mathrm{ER} \mathrm{Ca}^{2+}$ dyshomeostasis and ER stress induced by endogenously reduced SERCA2 function ${ }^{25-28}$, are prone to heart failure.

\section{Methods}

Clinical study. Study design. A cross-sectional case-control study design was implemented in which we at one time-point measured cardiac function by heart failure markers $\mathrm{N}$-terminal pro-brain natriuretic peptide (NT-proBNP), Galectin-3, suppression of tumorigenicity 2 (ST2), and troponin T as well as ECG and blood lipids (triglycerides, cholesterol including HDL and LDL). The rational for including troponin T was that it can be elevated in heart failure ${ }^{29}$ in addition to its use in detecting myocardial infarction.

Study group. The study included 25 patients with DD and 25 healthy volunteers matched by age, sex and body mass index (BMI). Age matching was made in \pm 5 -year intervals and BMI was matched according to four categories: $<18.5,18.5-24.99,25-29.99$ and $>30$. During 2017-2018 DD subjects were recruited mainly from the Dermato-Venereology clinic at Karolinska University Hospital in Stockholm, Sweden, and through study participants since it is most often a familial condition. Control subjects were recruited through advertisements by e-mail and online as well as from a primary healthcare clinic in Stockholm. Inclusion criteria for the study were typical skin symptoms combined with histopathology-verified DD or family history of DD. Exclusion criteria were pregnancy, oral corticosteroids, recent acute illness (past 4 weeks), active substance abuse and severe kidney or liver disease. All patients but one was previously tested for ATP2A2 mutations by whole exome and Sanger sequencing as previously described ${ }^{30}$.

Clinical assessment. Patients underwent a history taking focused on DD debut and family history. Family history was defined as having a first or second degree relative with DD. DD is most often treated with acitretin, an oral retinoid. Subjects who had been on oral acitretin treatment at some point during the 6 months prior to participation were classified into the acitretin category. Weight $(\mathrm{kg})$ and height $(\mathrm{cm})$ was measured to calculate BMI. The skin was inspected to verify the DD clinical diagnosis.

Collection of samples. Blood samples were collected after an overnight $(10 \mathrm{~h})$ fast. Since acitretin has a half-life of approximately 50 hours and is known to influence triglycerides and cholesterol ${ }^{31-33}$, subjects on oral acitretin discontinued the medication 7 days before the visit, longer wash-outs were not considered ethically.

Analytical techniques. Plasma NT-proBNP and troponin T was measured by immunochemistry and ElectroChemiLuminescence ImmunoAssay, and plasma triglycerides, cholesterol and HDL measured by enzymatic reaction and photometry (all using Cobas 6000, Roche Diagnostics Scandinavia AB, Stockholm, Sweden). Serum Galectin-3 and ST2 were determined using ELISA and photometry (Sunrise absorbance reader, Tecan Group Ltd., Männedorf, Zürich, Switzerland). LDL and HDL/LDL ratio were estimated from total cholesterol and HDL.

Population-based cohort study. We conducted a cohort study based on linkage between several Swedish registers. The Total Population Register contains demographic information on all individuals registered as Swedish inhabitants since 1968. The National Patient Register ${ }^{34}$ contains discharge diagnoses for all inpatient care episodes since 1973, and for outpatient treatment since 2001. Diagnoses are assigned by physicians according to the WHO's classification systems ICD- 9 and ICD- $10^{35-37}$. DD was defined by a diagnosis of the disorder according to the ICD-9 (757D) or ICD-10 (Q82.8E) in the National Patient Register. A total of 935 individuals with DD were identified. and matched with up to 100 comparison individuals selected randomly from the general population. Matching variables were birth year, sex and county of residence at the time of the first diagnosis in the DD index 


\begin{tabular}{|c|c|c|c|}
\hline Baseline Characteristics & DD Patients & Control Patients & P-Value \\
\hline$n$ & 25 & 25 & \\
\hline Age (years) & $52 \pm 13(27-78)$ & $51 \pm 13(27-76)$ & $0,80^{\#}$ \\
\hline Male sex (total number) & $10(40)$ & $10(40)$ & $1,000^{\dagger}$ \\
\hline BMI $\left(\mathrm{kg} / \mathrm{m}^{2}\right)$ & $28,2 \pm 5,3(18,9-42,3)$ & $\begin{array}{l}27,0 \pm 5,0 \\
(19,8-38,7)\end{array}$ & $0,45^{\#}$ \\
\hline Weight $(\mathrm{kg})$ & $81,4 \pm 17,8(54-119)$ & $\begin{array}{l}78,8 \pm 18.2 \\
(49,3-117)\end{array}$ & $0,73^{\#}$ \\
\hline Height $(\mathrm{cm})$ & $169,6 \pm 9,9(152-193)$ & $\begin{array}{l}170,3 \pm 11,5 \\
(148,5-193)\end{array}$ & $0,83^{\#}$ \\
\hline Current smoker & $5(20)$ & $2(8)$ & $0,417^{\dagger}$ \\
\hline DM family history & $13(52)$ & $11(44)$ & $0,778^{\dagger}$ \\
\hline Acitretin treatment & $14(56)$ & $0(0)$ & $<0,001^{\dagger}$ \\
\hline Hypertension treatment & $3(12)$ & $4(16)$ & $1,000^{\dagger}$ \\
\hline Dyslipidemia treatment & $3(12)$ & $2(8)$ & $1,000^{\dagger}$ \\
\hline $\begin{array}{l}\text { MutatioN related to treatment in } \\
\text { DD patients }(n=25)\end{array}$ & Pathogenic Mutation & $\begin{array}{l}\text { Benign/ } \\
\text { Unknown/ } \\
\text { No Mutation }\end{array}$ & $\begin{array}{l}\text { Mutation Not } \\
\text { Analyzed }\end{array}$ \\
\hline Acitretin treatment & 9 & 4 & 1 \\
\hline Isotretinoin treatment & 3 & 0 & 0 \\
\hline No systemic treatment & 4 & 2 & 2 \\
\hline Retinoid treatment \% of total & $75 \%$ & $67 \%$ & $33 \%$ \\
\hline
\end{tabular}

Table 1. Baseline characteristics of participants. Continuous variables were expressed as mean \pm standard deviation (minimum-maximum). Other was expressed as number (total number) of criteria. Categorical values were expressed as a number (\%). ${ }^{\#}$ Mann-Whitney U Test; ${ }^{\dagger}$ Fisher's Exact Test; DD, Darier disease; n, number; BMI, body mass index; DM, diabetes mellitus.

subject. Comparison individuals did not have a diagnosis of DD at the date of the first diagnosis of their respective index subjects with DD. Heart diseases were defined as a diagnosis of myocardial infarction (I21), heart failure (I50), or arrhythmia (I49) in ICD-10. While we are not aware of any validation of these specific diagnoses, most diagnoses of chronic diseases in the National Patient Register typically have positive predictive values between $85-95 \%{ }^{34}$.

Statistical analysis. In the clinical study descriptive analyses were performed to show frequencies, means, upper and lower limit and standard deviations. Since there were a small number of observations, Wilcoxon signed-rank test was used to compare continuous variables between groups. Differences between categorical variables were tested for significance using Fisher's exact test. $P$-values $<0.05$ were considered statistically significant. Demographic data (genetic background and presence of acitretin) were analyzed using two-way ANOVA and Bonferroni to correct for multiple comparisons. Data was analyzed by GraphPad Prism version 7.03 for Windows (GraphPad Software, La Jolla, CA, USA), and SPSS version 24.0 for Mac (SPSS, IBM, Armonk, NY, USA). The matched cohort design was used to examine associations between DD and heart disease. Odds ratios were estimated with conditional logistic regressions in SAS version 9.3 (SAS Institute, Cary, NC). In this design, odds ratios can be regarded as risk ratios, due to the incidence density sampling procedure. In additional analyses, we adjusted the results for the potential effects of cardiovascular risk factors of heart diseases, and alcohol misuse.

Ethics. The study was approved by the Regional Ethics Committee in Stockholm and carried out in accordance with relevant guidelines and regulations such as the Helsinki declaration. All patients provided written confirmed consent for the clinical study.

\section{Results}

Patient baseline characteristics. Comparisons of baseline clinical parameters between subjects with DD and healthy control subjects are given in Table 1; no significant differences were found between cases and controls, except acitretin use, thus indicative of good matching. Two DD patients were adopted and heredity was unknown. There were no major differences in acitretin treatment between DD patients, sub-grouped by mutation type.

Heart failure biomarkers. We analysed several biomarkers for heart failure including the gold standard NT-proBNP as well as the novel heart failure biomarkers ST2 and Galectin- $3^{38,39}$ (Table 2). Moreover, we measured Troponin T, which is a biomarker for cardiac necrosis in acute coronary syndrome; however, this can also be elevated in heart failure ${ }^{29}$. All these markers were within the normal range and with no significant differences between DD patients with or without mutation and control subjects (Table 2) and DD patients on acitretin did not show any significant differences (Supp. Table 1).

Electrocardiogram (ECG). A resting ECG was recorded to detect alterations in cardiac electrophysiology and analysed as shown in Table 3. While there was a significant increase above the normal upper range of $440 \mathrm{~ms}$ in QT-interval in DD patients with mutations, this was not found in frequency corrected QT-interval (QTc). 


\begin{tabular}{|l|l|l|l|}
\hline & $\begin{array}{l}\text { Control } \\
(\mathbf{n = 2 5})\end{array}$ & $\begin{array}{l}\text { Benign } \\
\text { mutation } \\
(\mathbf{n = 9})\end{array}$ & $\begin{array}{l}\text { Pathogenic } \\
\text { mutation } \\
(\mathbf{n = 1 5})\end{array}$ \\
\hline NT-proBNP (ng/L) & $\begin{array}{l}88,7(11,0- \\
954,0) \\
\pm 186,6\end{array}$ & $\begin{array}{l}64,0 \\
(18,0-187,0) \\
\pm 55,4\end{array}$ & $\begin{array}{l}126,4 \\
(17,0-535,0) \\
\pm 144,3\end{array}$ \\
\hline ST2 $(\mu \mathrm{g} / \mathrm{mL})$ & $\begin{array}{l}28,3 \\
(12,7-48,2) \\
\pm 9,7\end{array}$ & $\begin{array}{l}28,4 \\
(19,5-37,8) \\
\pm 6,2\end{array}$ & $\begin{array}{l}32,3(20,4- \\
47,3) \pm 6,8\end{array}$ \\
\hline Galectin-3 ( $\mu \mathrm{g} / \mathrm{L})$ & $\begin{array}{l}14,7 \\
(7,5-34,7) \\
\pm 5,6\end{array}$ & $\begin{array}{l}13,2 \\
(9,5-20,5) \\
\pm 3,3\end{array}$ & $\begin{array}{l}14,6(9,2-18,3) \\
\pm 2,7\end{array}$ \\
\hline Trop T $(\mathrm{ng} / \mathrm{L})$ & $\begin{array}{l}5,4 \\
(5,0-8,0) \\
\pm 1,1\end{array}$ & $\begin{array}{l}7,0(6,0-9,0) \\
\pm 1,1\end{array}$ & $\begin{array}{l}9,0(5,0-17,0) \\
\pm 4,1\end{array}$ \\
\hline
\end{tabular}

Table 2. Heart biomarkers in DD patients and controls sub-grouped for ATP2A2 mutation. Note that no significant differences were found. Data are reported as mean (Min-Max) \pm SD. NT-proBNP, N-terminal pro-brain natriuretic peptide; Trop T, Troponin T; ST2, member of the interleukin 1 receptor family. Two-way ANOVA, Bonferroni were used for statistical analysis; however, there were no significant differences.

\begin{tabular}{|c|c|c|c|}
\hline & $\begin{array}{l}\text { Control } \\
(n=25)\end{array}$ & $\begin{array}{l}\text { Benign } \\
\text { Mutation } \\
(\mathbf{n}=9)\end{array}$ & $\begin{array}{l}\text { Pathogenic } \\
\text { Mutation } \\
(\mathrm{n}=15)\end{array}$ \\
\hline HR (bpm) & $\begin{array}{l}62,4 \\
(46,0-84,0) \\
\pm 10,0\end{array}$ & $\begin{array}{l}61,0 \\
(50,0-78,0) \\
\pm 10,3\end{array}$ & $\begin{array}{l}55,1(47,0- \\
80,0) \pm 7,7\end{array}$ \\
\hline PQ Interval (ms) & $\begin{array}{l}159,0 \\
(108,0- \\
208,0) \pm \\
24,0\end{array}$ & $\begin{array}{l}150,3 \\
(114,0- \\
180,0) \pm \\
22,3\end{array}$ & $\begin{array}{l}145,9 \\
(114,0-192,0) \\
\pm 19,9\end{array}$ \\
\hline QRS-Duration (ms) & $\begin{array}{l}93,5(74,0- \\
114,0) \pm \\
9,7\end{array}$ & $\begin{array}{l}96,0 \\
(80,0-116,0) \\
\pm 12,9\end{array}$ & $\begin{array}{l}102,9 \\
(88,0-118,0) \\
\pm 7,7\end{array}$ \\
\hline QT Interval (ms) & $\begin{array}{l}414,7 \\
(354,0- \\
464,0) \pm \\
26,4\end{array}$ & $\begin{array}{l}433,78 \\
(372,0- \\
552,0) \pm \\
55,0\end{array}$ & $\begin{array}{l}453,1 \\
(406,0-518,0) \\
\pm 34,3^{*}\end{array}$ \\
\hline QTc Interval (ms) & $\begin{array}{l}419,4 \\
(368,0- \\
455,0) \pm \\
22,8\end{array}$ & $\begin{array}{l}433,3 \\
(402,0- \\
560,0) \pm \\
48,9\end{array}$ & $\begin{array}{l}431,9 \\
(379,0-498,0) \\
\pm 33,8\end{array}$ \\
\hline
\end{tabular}

Table 3. ECG parameters in DD patients and controls subgrouped for ATP2A2 mutation. Data are reported as mean (Min-Max) $\pm \mathrm{SD}$, in milliseconds (ms) or beats per minute (bpm). HR, heart rate. Two-way ANOVA, Bonferroni were used for statistical analysis. ${ }^{*} \mathrm{p}<0.001$ control $v s$ pathogenic mutation.

However, among DD patients with acitretin treatment (irrespective of the mutation), there was a slight but statistically significant elevation of QT and QTc interval (Supp. Table 2).

Blood lipids. Blood lipids were measured due to their importance in heart disease and possible increase due to retinoid treatment ${ }^{31-33}$ (Table 4). Although within the normal interval there was a slight significant trend towards higher LDL/HDL ratio in DD patients with mutations and this was likely due to acitretin treatment as $\mathrm{LDL} / \mathrm{HDL}$ ratio was also elevated in the group of DD patients with acitretin treatment (irrespective of the mutation) (Supp. Table 3).

Association between Darier disease and common heart diseases. DD patients in general had a $59 \%$ higher risk of heart failure diagnosis, compared to undiagnosed matched individuals; risk ratio $1.59,95 \%$ confidence interval 1.16-2.19 (Table 5). HF in DD patients occured at younger ages, 6.9 years earlier than in the comparison subjects. There was no conclusive evidence for increased risks of arrhythmia or myocardial infarcation. When these three heart diagnoses (heart failure, myocardial infarcation and arrythmia) were lumped together, the risk of any heart diagnosis was elevated with $32 \%$ in DD patients (men and women grouped); risk ratio 1.32, $95 \%$ confidence interval 1.02-1.70 (Table 5). It appeared as this increased risk of heart disease was mainly caused by women as these showed increased risk of heart disease (heart failure, myocardial infarcation and arrythmia) of 59\%. The increased risk of HF (in men and women) was likely caused mainly by female risk increase as women showed increased risk of general heart disease however the study did not have enough power to conclude this. Moreover, as a number of risk factors are associated with development of cardiovascular disease and these may be overrepresented among DD patients we performed a second analysis in which cardiovascular risk factors were corrected for (Table 5). The main findings that heart failure is more common among DD patients and overall heart disease is more common among female DD patients were still significant ( $53 \%$ elevated risk). 


\begin{tabular}{|l|l|l|l|}
\hline & $\begin{array}{l}\text { Control } \\
(\mathbf{n = 2 5})\end{array}$ & $\begin{array}{l}\text { Benign } \\
\text { Mutation } \\
(\mathbf{n = 9})\end{array}$ & $\begin{array}{l}\text { Pathogenic } \\
\text { Mutation } \\
(\mathbf{n = 1 5})\end{array}$ \\
\hline LDL/HDL & $\begin{array}{l}2,1 \\
(0,9-4,3) \\
\pm 1,0\end{array}$ & $\begin{array}{l}2,4 \\
(1,1-5,20) \\
\pm 1,4\end{array}$ & $\begin{array}{l}3,1(1,4-9,5) \\
\pm 1,9 *\end{array}$ \\
\hline Triglycerides (mmol/L) & $\begin{array}{l}1,1 \\
(0,5-3,9) \\
\pm 0,7\end{array}$ & $\begin{array}{l}1,4 \\
(0,6-3,1) \\
\pm 0,8\end{array}$ & $\begin{array}{l}1,5(0,8-2,8) \\
\pm 0,6\end{array}$ \\
\hline Cholesterol (mmol/L) & $\begin{array}{l}5,3 \\
(3,6-7,0) \\
\pm 0,9\end{array}$ & $\begin{array}{l}5,4 \\
(3,3-7,9) \\
\pm 1,4\end{array}$ & $\begin{array}{l}5,6(4,2-7,7) \\
\pm 1,0\end{array}$ \\
\hline HDL (mmol/L) & $\begin{array}{l}1,7 \\
(0,8-2,6) \\
\pm 0,5\end{array}$ & $\begin{array}{l}1,5 \\
(1,0-2,2) \\
\pm 0,4\end{array}$ & $\begin{array}{l}1,4(0,6-2,0) \\
\pm 0,4\end{array}$ \\
\hline LDL (mmol/L) & $\begin{array}{l}3,1 \\
(2,0-5,1) \\
\pm 0,8\end{array}$ & $\begin{array}{l}3,2 \\
(1,6-5,4) \\
\pm 1,2\end{array}$ & $\begin{array}{l}3,6(2,6-5,7) \\
\pm 1,0\end{array}$ \\
\hline
\end{tabular}

Table 4. Blood lipid profile of DD patients and controls sub-grouped for ATP2A2 mutation. Data are reported as mean (Min-Max) $\pm \mathrm{SD}$. LDL, low- density lipoprotein; HDL, high-density lipoprotein. Two-way ANOVA, Bonferroni were used for statistical analysis. ${ }^{*} \mathrm{p}<0.001$ Pathogenic mutation $v$ s benign mutation.

\begin{tabular}{|c|c|c|c|c|c|c|c|c|c|}
\hline & \begin{tabular}{|l|}
$\begin{array}{l}\text { Individuals } \\
\text { with Darier } \\
\text { disease } \\
(\mathbf{n}=935)\end{array}$ \\
$\mathbf{n}(\%)$
\end{tabular} & \begin{tabular}{|l}
$\begin{array}{l}\text { Matched } \\
\text { comparison } \\
\text { individuals } \\
(\mathrm{n}=93,487)\end{array}$ \\
$\mathbf{n}(\%)$
\end{tabular} & $\begin{array}{l}\mathbf{R R}^{1} \\
(\mathrm{CI})\end{array}$ & P-value & $\begin{array}{l}\mathbf{R R}^{2} \\
(\mathrm{CI})\end{array}$ & P-value & $\begin{array}{l}\mathbf{R R}^{3 \S} \\
(\mathrm{CI})\end{array}$ & P-value & $\begin{array}{l}\text { Mean age } \\
\text { in years at } \\
1^{\text {st }} \text { heart } \\
\text { diagnosis } \\
\text { in Darier } \\
\text { patients/ } \\
\text { comparison } \\
\text { individuals }\end{array}$ \\
\hline $\begin{array}{l}\text { I21 } \\
\text { Myocardial } \\
\text { infarction }\end{array}$ & $29(3,10)$ & $2828(3,03)$ & $\begin{array}{l}1,03 \\
(0,70- \\
1,52)\end{array}$ & 0,88 & $\begin{array}{l}1,03 \\
(0,70- \\
1,52)\end{array}$ & 0.89 & $\begin{array}{l}0.95 \\
(0.64- \\
1.41)\end{array}$ & 0.80 & $65,9 / 71,9$ \\
\hline $\begin{array}{l}\text { I50 } \\
\text { Heart failure }\end{array}$ & $52(5,56)$ & $3616(3,87)$ & $\begin{array}{l}1,59 \\
(1,16- \\
2,19)\end{array}$ & 0,004 & $\begin{array}{l}1,58 \\
(1,15- \\
2,18)\end{array}$ & 0.0041 & $\begin{array}{l}1.53 \\
(1.11- \\
2.11)\end{array}$ & 0.009 & $70,0 / 76,9$ \\
\hline $\begin{array}{l}\text { I49 } \\
\text { Arrythmia }\end{array}$ & $15(1,60)$ & $1330(1,42)$ & $\begin{array}{l}1,13 \\
(0,68- \\
1,90)\end{array}$ & 0,64 & $\begin{array}{l}1,12 \\
(0,67- \\
1,89)\end{array}$ & 0.65 & $\begin{array}{l}1.10 \\
(0.65- \\
1.85)\end{array}$ & 0.72 & $67,9 / 61,4$ \\
\hline $\begin{array}{l}\text { Any heart } \\
\text { diagnosis (males } \\
\text { \& females) }\end{array}$ & $80(8,56) \#$ & $6504(6,96)$ & $\begin{array}{l}1,32 \\
(1,02- \\
1,70)\end{array}$ & 0,04 & $\begin{array}{l}1,31 \\
(1,01- \\
1,70)\end{array}$ & 0.04 & $\begin{array}{l}1.26 \\
(0.97- \\
1.65)\end{array}$ & 0.09 & \\
\hline Males & $36(9,63)$ & $3431(9,17)$ & $\begin{array}{l}1,07 \\
(0,73- \\
1,57)\end{array}$ & 0,74 & $\begin{array}{l}1,06 \\
(0,72- \\
1,56)\end{array}$ & 0.76 & $\begin{array}{l}1.10 \\
(0.74- \\
1.63)\end{array}$ & 0.65 & \\
\hline Females & $44(7,84)$ & $3073(5,48)$ & $\begin{array}{l}1,59 \\
(1,13- \\
2,25)\end{array}$ & 0,008 & $\begin{array}{l}1,59 \\
(1,13- \\
2,25)\end{array}$ & 0.008 & $\begin{array}{l}1.46 \\
(1.02- \\
2.08)\end{array}$ & 0.04 & \\
\hline
\end{tabular}

Table 5. Risk of common heart diseases in DD (central illustration). Risk ratios (RR) and corresponding 95\% confidence intervals (CI) expressing associations between heart disease diagnoses in individuals with Darier disease, compared with matched comparison individuals without Darier disease. Note that any heart diagnosis indicates all used heart diagnoses combined into one category. Note also that the total number of individuals with myocardial infarctions, heart failure or arrhythmia diagnoses was 97, while individuals with any heart diagnosis was 80 , as some DD patients had more than one diagnosis. RR1; crude risk ratio. RR2; risk ratio adjusted for a lifetime diagnosis of alcohol misuse (ICD-10 code F10). RR3; risk ratio adjusted for a lifetime diagnosis of heart disease risk factors. "Note that the total number of patients with either I21, I50 or I49 is higher than the total number of patients with any heart diagnosis as some patients had more than one diagnosis. ${ }^{\S}$ Heart disease risk factors and ICD10 codes: Z72.0, Z72.0W (Tobacco use), Z72.0A (Smoking), I10.9 (Essential hypertension), I15.9 (Secondary hypertension, E10 (Type 1 diabetes), E11(Type 2 diabetes), E78.5 (Hyperlipidemia), E78.0 (Pure hypercholesterolemia), E78.1 (Pure hypertriglyceridemia), E78.2, E78.2×(Mixed hyperlipidemia), E78.0A (Familial hypercholesterolemia), E66.0, E66.8, E66.9 (Obesity).

\section{Discussion}

While our clinical study found no heart abnormalites in DD patients our population study indicates that DD patients are more prone to develop HF and at an earlier age. Possible reasons behind the observed excess risk of HF in DD are outlined below.

SERCA2 and heart disease. DD is mainly caused by a mutation in the ATP2A2 gene ${ }^{7}$, which encodes for the SR/ER Ca ${ }^{2+}$ pump- SERCA2. To better understand and further characterize the consequenses of SERCA2 dysfunction in DD patients, we searched for more common conditions in which SERCA2 plays a central role and 
chose to focus on heart disease, as the importance of SERCA2 in heart function is well established. In both animal and human heart failure, SERCA2a expression is significantly decreased, which leads to abnormal $\mathrm{Ca}^{2+}$ handling and a deficient contractile state and $\mathrm{HF}^{40}$. Interestingly, SERCA2 haplosufficent mice were reported to develop $\mathrm{HF}$ when crossed with a with a transgenic model of increased myofibrillar $\mathrm{Ca}^{2+}$-sensitivity ${ }^{41-43}$, thus suggesting that DD patients may be more susceptible to HF. Further, in attempts to rescue SERCA2a deficiency phenotype, a gene-targeted mouse with full substitution of the cardiac isoform SERCA2a by SERCA2 $b$ was described ${ }^{44}$. The $2 \mathrm{~b}$ isoform has a nearly 2 -fold higher affinity for $\mathrm{Ca}^{2+}$ but a lower maximal catalytic turnover rate than $2 \mathrm{a}$, which resulted in a mild concentric heart hypertrophy and impaired contraction-relaxation. This suggests that also dysfunctional and not only defiency in SERCA2 may cause HF. Importantly, Atp $2 a 2^{-1+}$ mice develop squamous cell carcinomas but no DD-like lesions, thus mouse SERCA2 pathophysiology may therefore differ substantially from humans ${ }^{45}$. Our study presents the first evidence that HF is accociated with DD which adds to the growing body of evidence that DD is a systemic condition not only confined to the skin. This finding also adds a novel angle to understanding of SERCA2 pathophysiolog in human HF.

Gender differences in heart failure. Our findings indicates that DD female patients have higher risk for heart disease in general and probably specifically for heart failure. In fact, over the past decade, one of the most robust findings across numerous HF studies was a distinct difference in gender distribution. Namely, women significantly outnumber men, leading to a gender ratio of approximately 2:1 in HF, with preserved ejection fraction $^{46,47}$. While we do not know what subtype of HF is overrepresentend in DD female patients, these gender differences in HF may be explained by the presence of dysfunctional SERCA2 as it has been shown in multiple separate studies that increased oxidative stress observed in damaged myocardium lead to impairment of the SERCA pump followed by $\mathrm{Ca}^{2+}$ dyshomeostasis and prolonged diastolic relaxation, which contributed to the females' predominent heart failure type $\mathrm{e}^{41-43}$.

Confounding factors. An alternative explanation to the DD-HF correlation might be the long term usage of acitretin to treat DD, that makes these patients more susceptible to HF. Acitretin is a vitamin A derivative and a second generation retinoid which has anti-inflammatory and immunomodulatory effects ${ }^{48}$. Among the side effects associated with this drug, it has been reported that treatment with acitretin increases serum lipids and triglycerides in $25-50 \%$ of patients ${ }^{49,50}$, however the DD-HF association did not change significantly after correction for cardiovascular risk factors including hyperlipidemia and hypertriglyceridemia (Table 5). Another possible explanation for our DD-HF findings may lie in the fact that chronic skin disease by itself may increase the risk of cardiovascular disease ${ }^{51}$. Because the national registers in the cohort study lacked potentially important individual lifestyle characteristics, the results from these analyses warrant replication in a more informative data set where statistical adjustment for such factors are possible.

\section{Conclusions}

DD is likely a syndrome with multi-organ involvement. The association between DD and HF we demonstrated here can be further understood in several ways. Most important will be to characterize what kind of heart failure DD patients have, in order to tailor treatment. Careful assessment of heart function in healthy individuals would further increase our understanding of SERCA2 in normal heart physiology. Importantly, it may be that DD would require systemic treatment from early age to combat multi-organ involvement however before that can be realized we must further map the its' organ involvement. Moreover, there is currently no therapy available for such treatment.

Clinical perspectives. The increased risk of heart failure should be considered in patients with DD that although being a rare disease affects around 200,000 patients worldwide. While speculative, it may be that heart failure in DD show special characteristics.

Translational outlook. This study adds significant human evidence for a role of SERCA2 in heart failure and adds to the growing body of literature suggesting SERCA2 as a potential terapeutic target.

\section{Data availability}

The datasets generated during and/or analysed during the current study are available from the corresponding author on reasonable request.

Received: 20 January 2020; Accepted: 3 April 2020;

Published online: 23 April 2020

\section{References}

1. Goldstein, J. L. \& Brown, M. S. Regulation of low-density lipoprotein receptors: implications for pathogenesis and therapy of hypercholesterolemia and atherosclerosis. Circulation 76(3), 504-7 (1987).

2. Lehrman, M. A. et al. Alu-Alu recombination deletes splice acceptor sites and produces secreted low density lipoprotein receptor in a subject with familial hypercholesterolemia. J Biol Chem 262(7), 3354-61 (1987).

3. Gahl, W. A. The battlefield of rare diseases: where uncommon insights are common. Sci Transl Med, 4(154), 154ed7 (2012).

4. Hovnanian, A. Darier's disease: from dyskeratosis to endoplasmic reticulum calcium ATPase deficiency. Biochem Biophys Res Commun 322(4), 1237-44 (2004).

5. Burge, S. M. \& Wilkinson, J. D. Darier-White disease: a review of the clinical features in 163 patients. J Am Acad Dermatol 27(1), $40-50$ (1992)

6. Cooper, S. M. \& Burge, S. M. Darier's disease: epidemiology, pathophysiology, and management. Am J Clin Dermatol 4(2), 97-105 (2003).

7. Sakuntabhai, A. et al. Mutations in ATP2A2, encoding a Ca2+ pump, cause Darier disease. Nat Genet 21(3), 271-7 (1999).

8. Sehgal, V. N. \& Srivastava, G. Darier’s (Darier-White) disease/keratosis follicularis. Int J Dermatol 44(3), 184-92. (2005). 
9. Munro, C. S. The phenotype of Darier's disease: penetrance and expressivity in adults and children. Br J Dermatol 127(2), 126-30. (1992).

10. Gordon-Smith, K. et al. The neuropsychiatric phenotype in Darier disease. Br J Dermatol 163(3), 515-22 (2010).

11. Cederlof, M. et al. Intellectual disability and cognitive ability in Darier disease: Swedish nation-wide study. Br J Dermatol 173(1), $155-8$ (2015).

12. Savignac, M. et al. Darier disease: a disease model of impaired calcium homeostasis in the skin. Biochim Biophys Acta 1813(5), 1111-7 (2011).

13. Lam, C. S. et al. Epidemiology and clinical course of heart failure with preserved ejection fraction. Eur J Heart Fail 13(1), 18-28 (2011).

14. Baker, D. L. et al. Targeted overexpression of the sarcoplasmic reticulum $\mathrm{Ca}^{2+}$-ATPase increases cardiac contractility in transgenic mouse hearts. Circ Res 83(12), 1205-14 (1998).

15. del Monte, F. et al. Restoration of contractile function in isolated cardiomyocytes from failing human hearts by gene transfer of SERCA2a. Circulation 100(23), 2308-11 (1999).

16. Studeli, R. et al. Diastolic dysfunction in human cardiac allografts is related with reduced SERCA2a gene expression. Am J Transplant 6(4), 775-82 (2006).

17. Jessup, M. et al. Calcium Upregulation by Percutaneous Administration of Gene Therapy in Cardiac Disease (CUPID): a phase 2 trial of intracoronary gene therapy of sarcoplasmic reticulum Ca2+-ATPase in patients with advanced heart failure. Circulation 124(3), 304-13 (2011).

18. Greenberg, B. et al. Calcium upregulation by percutaneous administration of gene therapy in patients with cardiac disease (CUPID 2): a randomised, multinational, double-blind, placebo-controlled, phase $2 \mathrm{~b}$ trial. Lancet 387(10024), 1178-86 (2016).

19. Kawase, Y. et al. Reversal of cardiac dysfunction after long-term expression of SERCA2a by gene transfer in a pre-clinical model of heart failure. J Am Coll Cardiol 51(11), 1112-9 (2008).

20. Hotamisligil, G. S. Endoplasmic reticulum stress and the inflammatory basis of metabolic disease. Cell 140(6), 900-17 (2010).

21. Szegezdi, E. et al. ER stress contributes to ischemia-induced cardiomyocyte apoptosis. Biochem Biophys Res Commun 349(4), 1406-11 (2006)

22. Nickson, P., Toth, A. \& Erhardt, P. PUMA is critical for neonatal cardiomyocyte apoptosis induced by endoplasmic reticulum stress. Cardiovasc Res 73(1), 48-56 (2007).

23. Azfer, A. et al. Activation of endoplasmic reticulum stress response during the development of ischemic heart disease. Am J Physiol Heart Circ Physiol 291(3), H1411-20 (2006).

24. Liu, X. H. et al. Cardiomyocyte-specific disruption of Serca2 in adult mice causes sarco(endo)plasmic reticulum stress and apoptosis. Cell Calcium 49(4), 201-7 (2011).

25. Dode, L. et al. Dissection of the functional differences between sarco(endo)plasmic reticulum Ca2+-ATPase (SERCA) 1 and 2 isoforms and characterization of Darier disease (SERCA2) mutants by steady-state and transient kinetic analyses. J Biol Chem 278(48), 47877-89 (2003)

26. Foggia, L. et al. Activity of the hSPCA1 Golgi $\mathrm{Ca}^{2+}$ pump is essential for $\mathrm{Ca}^{2+}$-mediated $\mathrm{Ca}^{2+}$ response and cell viability in Darier disease. J Cell Sci 119(Pt 4), 671-9 (2006).

27. Miyauchi, Y. et al. Comprehensive analysis of expression and function of 51 sarco(endo)plasmic reticulum Ca2+-ATPase mutants associated with Darier disease. J Biol Chem 281(32), 22882-95 (2006).

28. Savignac, M. et al. SERCA2 dysfunction in Darier disease causes endoplasmic reticulum stress and impaired cell-to-cell adhesion strength: rescue by Miglustat. J Invest Dermatol 134(7), 1961-70. (2014).

29. Wettersten, N. \& Maisel, A. Role of Cardiac Troponin Levels in Acute Heart Failure. Card Fail Rev 1(2), 102-106 (2015).

30. Leong, I. U. S. et al. Novel mutations in Darier disease and association to self-reported disease severity. PLoS One 12(10), e0186356 (2017).

31. Pilkington, T. \& Brogden, R. N. Acitretin. A review of its pharmacology and therapeutic use. Drugs 43(4), 597-627 (1992).

32. Gupta, A. K. et al. Side-effect profile of acitretin therapy in psoriasis. J Am Acad Dermatol 20(6), 1088-93 (1989).

33. Vahlquist, C., Selinus, I. \& Vessby, B. Serum lipid changes during acitretin (etretin) treatment of psoriasis and palmo-plantar pustulosis. Acta Derm Venereol 68(4), 300-5 (1988).

34. Ludvigsson, J. F. et al. External review and validation of the Swedish national inpatient register. BMC Public Health 11, 450 (2011).

35. WHO, World Health Organization. International Statistical Classification of Diseases and Related Health Problems (ICD-8) (1967).

36. WHO, World Health Organization. International Statistical Classification of Diseases and Related Health Problems (ICD-9) (1978).

37. WHO, World Health Organization. International Statistical Classification of Diseases and Related Health Problems (ICD-10) (1992)

38. Bhardwaj, A. \& Januzzi, J. L. Jr. ST2: a novel biomarker for heart failure. Expert Rev Mol Diagn 10(4), 459-64 (2010).

39. Gehlken, C. et al. Galectin-3 in Heart Failure: An Update of the Last 3 Years. Heart Fail Clin 14(1), 75-92 (2018).

40. Kawase, Y. \& Hajjar, R. J. The cardiac sarcoplasmic/endoplasmic reticulum calcium ATPase: a potent target for cardiovascular diseases. Nat Clin Pract Cardiovasc Med 5(9), 554-65 (2008).

41. Babusikova, E. et al. Age-associated changes in $\mathrm{Ca}(2+)$-ATPase and oxidative damage in sarcoplasmic reticulum of rat heart. Physiol Res 61(5), 453-60 (2012).

42. Lancel, S. et al. Oxidative posttranslational modifications mediate decreased SERCA activity and myocyte dysfunction in Galphaqoverexpressing mice. Circ Res 107(2), 228-32 (2010).

43. Prasad, V. et al. SERCA2 Haploinsufficiency in a Mouse Model of Darier Disease Causes a Selective Predisposition to Heart Failure. Biomed Res Int 2015, 251598 (2015).

44. Ver Heyen, M. et al. Replacement of the muscle-specific sarcoplasmic reticulum $\mathrm{Ca}(2+)$-ATPase isoform SERCA2a by the nonmuscle SERCA2b homologue causes mild concentric hypertrophy and impairs contraction-relaxation of the heart. Circ Res 89(9), 838-46 (2001).

45. Liu, L. H. et al. Squamous cell tumors in mice heterozygous for a null allele of Atp2a2, encoding the sarco(endo)plasmic reticulum Ca2+-ATPase isoform 2 Ca2 + pump. J Biol Chem 276(29), 26737-40 (2001).

46. Borlaug, B. A. \& Redfield, M. M.Diastolic and systolic heart failure are distinct phenotypes within the heart failure spectrum. Circulation (2011). 123(18): p. 2006-13; discussion (2014).

47. Scantlebury, D. C. \& Borlaug, B. A. Why are women more likely than men to develop heart failure with preserved ejection fraction? Curr Opin Cardiol 26(6), 562-8 (2011).

48. Kaushik, S. B. \& Lebwohl, M. G. Review of safety and efficacy of approved systemic psoriasis therapies. Int J Dermatol (2018).

49. Hugh, J. et al. From the Medical Board of the National Psoriasis Foundation: The risk of cardiovascular disease in individuals with psoriasis and the potential impact of current therapies. J Am Acad Dermatol 70(1), 168-77 (2014).

50. McKenna, D. B. \& Murphy, G. M. Skin cancer chemoprophylaxis in renal transplant recipients: 5 years of experience using low-dose acitretin. Br J Dermatol 140(4), 656-60 (1999).

51. Mehta, N. N. et al. Patients with severe psoriasis are at increased risk of cardiovascular mortality: cohort study using the General Practice Research Database. Eur Heart J31(8), 1000-6 (2010). 


\section{Acknowledgements}

We thank the participating patients, research nurse Helena Ghriesel and all funding agencies (Vetenskapsrådet, Hudfonden, Svenska Sällskapet för medicinsk forskning, ALF medicin Stockholm, Jeanssons stiftelse, Tore Nilssons Stiftelse). Open access funding provided by Karolinska Institute.

\section{Author contributions}

All authors contributed to study design. T.A., M.C., H.L., P.C., I.U.S.L. and E.B.W. collected the data. E.B.W., T.A. and P.C. performed data analysis. E.B.W., P.C., M.C., T.A., H.L. and J.D.W. contributed to writing.

\section{Competing interests}

The authors declare no competing interests.

\section{Additional information}

Supplementary information is available for this paper at https://doi.org/10.1038/s41598-020-63832-9.

Correspondence and requests for materials should be addressed to J.D.W.

Reprints and permissions information is available at www.nature.com/reprints.

Publisher's note Springer Nature remains neutral with regard to jurisdictional claims in published maps and institutional affiliations.

(c) (i) Open Access This article is licensed under a Creative Commons Attribution 4.0 International License, which permits use, sharing, adaptation, distribution and reproduction in any medium or format, as long as you give appropriate credit to the original author(s) and the source, provide a link to the Creative Commons license, and indicate if changes were made. The images or other third party material in this article are included in the article's Creative Commons license, unless indicated otherwise in a credit line to the material. If material is not included in the article's Creative Commons license and your intended use is not permitted by statutory regulation or exceeds the permitted use, you will need to obtain permission directly from the copyright holder. To view a copy of this license, visit http://creativecommons.org/licenses/by/4.0/.

(C) The Author(s) 2020 